\title{
RESISTENCIA ANTIMICROBIANA DE CEPAS DE Bartonella bacilliformis PROCEDENTES DE REGIONES ENDÉMICAS DE LA ENFERMEDAD DE CARRIÓN EN EL PERÚ
}

\author{
Giovanna Mendoza-Mujica1,a, Diana Flores-León ${ }^{1, b}$
}

\section{RESUMEN}

Objetivos. Evaluar la susceptibilidad antimicrobiana in vitro a cloranfenicol (CHL) y ciprofloxacino (CIP) de cepas de Bartonella bacilliformis procedentes de áreas endémicas de la enfermedad de Carrión (EC) en el Perú, mediante tres métodos de laboratorio. Materiales y métodos. Se evaluó la susceptibilidad antimicrobiana a CHL y CIP de 100 cepas de Bartonella bacilliformis, los aislamientos procedieron de pacientes de los departamentos de Ancash, Cusco, Cajamarca, Lima y La Libertad; las cepas se evaluaron mediante: disco difusión, E-Test y dilución en agar. Resultados. El $26 \%$ de las cepas de Bartonella bacilliformis evaluadas, presentaron resistencia a CIP y $1 \%$ a CHL. Se obtuvieron patrones similares de sensibilidad/resistencia antimicrobiana en los tres métodos utilizados. Conclusiones. Las cepas de Bartonella bacilliformis circulantes en el Perú, presentan elevados niveles de resistencia in vitro a CIP, por lo que se recomienda ampliar la investigación sobre la utilización del fármaco en los esquemas de tratamiento de la EC. Los métodos de E-test y disco difusión resultaron más convenientes para la evaluación de la susceptibilidad antimicrobiana in vitro del microorganismo.

Palabras clave: Bartonella bacilliformis; Ciprofloxacino; Cloranfenicol; Pruebas antimicrobianas de difusión por disco; Recuento de dilución agar (fuente: DeCS BIREME).

\section{ANTIMICROBIAL RESISTANCE OF Bartonella bacilliformis STRAINS FROM REGIONS ENDEMIC TO BARTONELLOSIS IN PERU}

\begin{abstract}
Objectives. To evaluate in vitro antimicrobial susceptibility to chloramphenicol (CHL) and ciprofloxacin (CIP) in strains of Bartonella bacilliformis from areas that are endemic to Bartonellosis in Peru, through three laboratory methods. Materials and methods. Antimicrobial susceptibility to $\mathrm{CHL}$ and CIP from 100 strains of Bartonella bacilliformis isolated in patients from the regions of Ancash, Cusco, Cajamarca, Lima and La Libertad were evaluated. Strains were evaluated by: disk diffusion, E-test and agar dilution. Results. $26 \%$ of the strains of Bartonella bacilliformis evaluated were resistant to CIP and $1 \%$ to $\mathrm{CHL}$. Similar patterns of antimicrobial sensitivity / resistance were obtained in all three methods. Conclusions. Bartonella bacilliformis strains circulating in Peru have high levels of in vitro resistance to CIP, so it is advisable to expand research on the use of drug treatment regimens of the Bartonellosis. The methods of E-test and disk diffusion were the most suitable for assessment in vitro of antimicrobial susceptibility of the microorganism.
\end{abstract}

Key words: Bartonella bacilliformis; Ciprofloxacin; Chloramphenicol; Disk diffusion antimicrobial tests; Agar dilution count (source: MeSH NLM).

\section{INTRODUCCIÓN}

Bartonella baciliformis es el agente etiológico de la enfermedad de Carrión (EC), transmitida por mosquitos del género Lutzomyia. La EC es endémica de Perú, Colombia y Ecuador (1); países que tienen como característica geográfica común la presencia de valles y quebradas formadas por la cordillera de los Andes, donde se presentan condiciones óptimas de temperatura, humedad, y altitud, para convertirse en nichos ecológicos del vector ${ }^{(1)}$. Numerosos estudios han determinado que individuos asintomáticos, residentes en áreas de alta endemicidad de la EC sirven como reservorios de la enfermedad, puesto que hasta el momento la infección no ha sido detectada en especies animales ${ }^{(2)}$.

Ante la ausencia de reportes de casos de EC en los países vecinos los últimos años, el Perú es el único país endémico con reportes en 11 de sus 24 departamentos, y reemergencia reciente en zonas de extrema pobreza de Lima, Ancash, La Libertad, Piura y Cusco, lugares donde actualmente es considerada endémica ${ }^{(3)}$.

\footnotetext{
Laboratorio de Metaxénicas Bacterianas, Área Bartonelosis. Centro Nacional de Salud Pública. Instituto Nacional de Salud. Lima, Perú.

Bióloga, magíster en Microbiología Clínica; ${ }^{\mathrm{b}}$ bióloga

Recibido: : 13-08-15 Aprobado: 21-10-15
}

Citar como: Mendoza-Mujica G, Flores-León D. Resistencia antimicrobiana de cepas de Bartonella bacilliformis procedentes de regiones endémicas de la enfermedad de Carrión en el Perú. Rev Peru Med Exp Salud Publica. 2015;32(4):659-66. 
La EC se presenta en dos síndromes clínicos, forma febril anemizante (fiebre de la Oroya) y forma eruptiva (verruga peruana). La severidad de la enfermedad depende del estado inmunológico del huésped, algunos pacientes pueden presentar $100 \%$ de eritrocitos infectados, con anemia severa de consecuencias fatales. Son frecuentes en los casos graves de la enfermedad, las infecciones oportunistas sobreagregadas que pueden incrementar los porcentajes de morbimortalidad. En las áreas endémicas de extrema pobreza, la población más afectada por la fase crónica eruptiva es la infantil, quienes presentan lesiones eruptivas proliferativas en la piel; representando los principales reservorios de la enfermedad ${ }^{(2,3)}$.

El Ministerio de Salud del Perú, estableció años atrás la terapia antimicrobiana para la EC, recomendando la dosis y tiempo de tratamiento, de acuerdo a la presentación clínica, empleando $\mathrm{CHL}$ para la forma febril anemizante y estreptomicina o rifampicina para la forma eruptiva ${ }^{(4)}$. Debido a reportes de fallas terapéuticas y bacteremia persistente en pacientes tratados con $\mathrm{CHL}$ en zonas endémicas, se actualizó la guía clínica de tratamiento, recomendando la utilización de quinolonas de segunda generación, como CIP para el tratamiento de la fase aguda de la enfermedad ${ }^{(4,5)}$. Sin embargo, los últimos años se ha reportado persistencia bacteriológica de Bartonella bacilliformis en pacientes tratados con este fármaco, habiéndose estudiado una cohorte de 62 pacientes, de los cuales 22,6\%, presentaron cultivos positivos postratamiento, (6) lo que podría estar relacionado con diferentes mecanismos por los cuales el microorganismo genera resistencia a CIP.

Investigaciones desarrolladas han descrito los mecanismos bacterianos de resistencia a las quinolonas, por mutaciones o sustituciones de aminoácidos en las sitios diana de las posiciones Ala91, Asp95 del gen gyrA, y Ala85, Asp89 en parC; como las producidas en Escherichia coli en Ala83 y Ala 80, respectivamente. En Bartonella bacilliformis esta característica es intrínseca y le confiere resistencia constitutiva al ácido nalidíxico (quinolona de primera generación), por alteraciones en la hidrofobicidad de las dianas, dificultando la interacción del antimicrobiano ${ }^{(7-9)}$; haciéndose necesario, como un mecanismo de control y evaluación de la susceptibilidad antimicrobiana del agente etiológico de la EC, la implementación de un sistema de vigilancia de la resistencia antimicrobiana de Bartonella bacilliformis; con la finalidad de reajustar los algoritmos terapéuticos ${ }^{(1,10)}$. Sin embargo, estas actividades no pueden desarrollarse en laboratorios cercanos a las áreas endémicas, debido a las características especiales de este microorganismo para su cultivo, aislamiento y requerimientos nutricionales, por lo que se requiere laboratorios especializados para su ejecución ${ }^{(10)}$.

Los protocolos de métodos de laboratorio para la determinación de la susceptibilidad antimicrobiana descritos actualmente en las guías internacionales, consideran únicamente otras especies de Bartonella, puesto que los casos de EC y su agente etiológico, Bartonella bacilliformis, actualmente, son reportadas únicamente en el Perú. Quizá por ello son pocos los estudios realizados sobre susceptibilidad antimicrobiana hasta el momento, que tienen además el inconveniente de haber incluido muy pocas cepas en la evaluación, por lo que no expresan la situación real de la resistencia antimicrobiana de cepas de Bartonella bacilliformis ${ }^{(13,14)}$.

Entre los métodos empleados para evaluar la susceptibilidad antimicrobiana de bacterias de difícil crecimiento, el de disco difusión es el más utilizado, sin embargo, no permite la evaluación de Bartonella bacilliformis en condiciones usuales, por ello se requiere la adecuación del método así como plantear otras alternativas ${ }^{(11)}$. Considerando estos aspectos, la presente investigación buscó establecer la resistencia in vitro de cepas de Bartonella bacilliformis provenientes de muestras extraídas de pacientes de zonas endémicas del país, evaluando la susceptibilidad a CIP y $\mathrm{CHL}$, mediante métodos de laboratorio especialmente diseñados para la evaluación de la susceptibilidad antimicrobiana de cepas de Bartonella bacilliformis.

\section{MATERIALES Y MÉTODOS}

Se realizó un estudio transversal, que incluyó a cien cepas de Bartonella bacilliformis del cepario del Área de Bartonelosis del Laboratorio de Referencia Nacional Metaxénicas Bacterianas, del Instituto Nacional de Salud-Perú, aisladas de pacientes de departamentos endémicos, durante junio de 2005 a diciembre de 2011.

La selección de los aislamientos se realizó mediante un muestreo aleatorio simple de acuerdo con la disponibilidad de cepas por área endémica, se incluyeron cepas obtenidas de brotes de la EC: 30 de HuarochiríLima (2005); 20 de Jaén y Chota-Cajamarca (2007); 30 de Quillabamba-Cusco (2008-2009); 15 de Caraz-Ancash (2011), y 05 de Pataz-La Libertad (2011). Se realizó la evaluación de la totalidad de aislamientos disponibles de Ancash, Cajamarca y La Libertad (40 cepas).

La evaluación de la susceptibilidad antimicrobiana in vitro de cepas de Bartonella bacilliformis a cloranfenicol (CHL) y ciprofloxacino (CIP), se desarrolló mediante tres métodos microbiológicos: Disco difusión, E-Test y Dilución en agar, los cuales fueron especialmente acondicionados para el microorganismo. Como cepas control se utilizaron cepas referenciales ATCC35685 de Bartonella bacilliformis y 25922 de Escherichia coli.

\section{REACTIVACIÓN DE CEPAS}

Se retiraron de la congeladora a $-80{ }^{\circ} \mathrm{C}$, cepas criopreservadas de Bartonella bacilliformis, las cuales 
fueron inoculadas en medio bifásico con la fase sólida agar Columbia(Oxoid), 0,25\% de extracto de levadura (Difco)y $10 \%$ de sangre de carnero desfibrinada y RPMI 1640 (Gibco) con L-glutamina y bicarbonato de sodio en la fase líquida; los frascos inoculados fueron incubados de $28-30^{\circ} \mathrm{C}$ durante 4 a 5 días, después de los cuales se realizaron subcultivos en placas de agar sangre Columbia inoculando $0,5 \mathrm{~mL}$ de fase líquida a partir de los cultivos positivos. Las placas fueron incubadas de 28-30 ${ }^{\circ} \mathrm{C}$ durante 3-4 días, hasta obtener crecimiento confluente de colonias del microorganismo.

\section{EVALUACIÓN DE LA SUSCEPTIBILIDAD}

Preparación de placas de susceptibilidad para los métodos de disco difusión y E-test. Para la evaluación in vitro de la susceptibilidad antimicrobiana de las cepas de Bartonella bacilliformis a CHL y CIP, se modificaron y adecuaron los procedimientos de los métodos de susceptibilidad, períodos de incubación y medio de cultivo a emplear. Para los métodos de disco difusión y E-test, se prepararon placas de agar Columbia suplementado con $10 \%$ de sangre desfibrinada de carnero, el volumen dispensado de agar por placa fue de $35 \mathrm{~mL}$, con una altura del medio de $4 \mathrm{~mm}$ recomendado por el Clinical and Laboratory Standards Institute (CLSI).

Preparación de placas con diluciones del antimicrobiano. Se realizaron diluciones de los antibióticos (droga activa) CHL y CIP (®Sigma) en rangos decrecientes de la concentración de cada antimicrobiano de 128 - 0,0312ug/mL. Cada dilución del antimicrobiano se homogenizó en el medio agar sangre Columbia con $10 \%$ de sangre de carnero y fue vertido en placas estériles.

Estandarización del inóculo para las técnicas de disco difusión y E-test. Se realizó la estandarización del inóculo bacteriano de Bartonella bacilliformis, a partir de una placa de subcultivo con crecimiento confluente de colonias del microorganismo, que fueron suspendidas en $5 \mathrm{~mL}$ de solución salina fisiológica estéril; ajustándose a un patrón de turbidez de 0,5 de la escala de Mc Farland, correspondiente a $1,5 \times 10^{8} \mathrm{UFC} / \mathrm{mL}$, e inmediatamente verificado con un turbidimetro.

Inoculación de placas para sensibilidad. Se distribuyó homogéneamente $0,5 \mathrm{~mL}$ del inóculo bacteriano estandarizado, en la superficie del agar sangre, con la finalidad de lograr un crecimiento confluente del microorganismo, una vez incorporado el inóculo en el medio, se colocaron los discos de susceptibilidad y tiras E-test de ambos antimicrobianos; las placas se incubaron de 28 a $30^{\circ} \mathrm{C}$ por 6 días.

Inoculación de placas con diluciones de antimicrobianos. Se estandarizaron los inóculos bacterianos de cada cepa a escala 0,5 de Mc Farland, cada inóculo fue diluido a concentración $1 / 100$, finalmente $400 \mu \mathrm{L}$ de cada dilución fue colocada individualmente en los pozos del replicador de Steers. Con el inoculador de Steers se dispensaron $10 \mu \mathrm{L}$ del inóculo bacteriano sobre la superficie de las placas de agar que contenían concentraciones crecientes de los antimicrobianos. Se llevaron las placas a incubación de $28-30^{\circ} \mathrm{C}$ por 6 días.

Lectura de placas de disco difusión. Se observaron las placas con luz indirecta y se midió cada halo de inhibición alrededor de los discos con antimicrobiano: CIP $5 \mu \mathrm{g} \mathrm{CHL} 30 \mu \mathrm{g}$ (囚Oxoid), los casos que presentaron crecimiento hasta el borde del disco se reportaron con el valor del diámetro del disco $(6 \mathrm{~mm})$, obtenidos los valores se reportaron las cepas como sensible o resistente.

Lectura de placas de E-test. Se utilizaron las tiras de $\mathrm{CHL}$ (rango 0,016-256 $\mu \mathrm{g} / \mathrm{mL}$ ) y CIP (rango: 0,002-32 $\mu \mathrm{g} / \mathrm{mL}$ ) (®Biomerux) se determinó la concentración mínima inhibitoria (CMI) del antimicrobiano observando la interfase de la elipse, formada entre el crecimiento bacteriano y la inhibición del mismo.

Lectura de placas de dilución en agar. Cumplidos los 6 días de incubación se observaron con luz directa las placas inoculadas, se observó el crecimiento en los puntos de inoculación, y se determinó las CMI en la concentración e identificando las diluciones del antibiótico, a partir de las cuales se inhibió totalmente el crecimiento bacteriano,

Determinación de los puntos de corte y zonas de inhibición para la susceptibilidad antimicrobiana de Bartonella bacilliformis. Ante la inexistencia de puntos de corte establecidos por el CLSI u otra institución internacional para Bartonella bacilliformis, el Laboratorio de Referencia Nacional de Metaxénicas Bacterianas del Instituto Nacional de Salud-Perú, siguiendo la metodología establecida por la British Society for Antimicrobial Chemotherapy (BSAC) determinó los puntos de corte de ambos antimicrobianos para los métodos de E-test y dilución en agar, considerando la información farmacocinética, obteniendo: CIP (sensible $\leq 0,5 \mu \mathrm{g} / \mathrm{mL}$ - resistente: $\geq 1$ $\mu \mathrm{g} / \mathrm{mL}$ ) y $\mathrm{CHL}$ (sensible: $\leq 0,5 \mu \mathrm{g} / \mathrm{mL}$ - resistente: $\geq 1$ $\mu \mathrm{g} / \mathrm{mL}$ ) y para el método de disco difusión (sensible $\geq$ $21 \mathrm{~mm}$ y resistente $\leq 20 \mathrm{~mm}$ ).

\section{ANÁLISIS DE DATOS}

Seguidamente, el análisis de los resultados obtenidos en la determinación de la susceptibilidad antimicrobiana de cada aislamiento, fue ingresada en el programa STATA v12.0 para obtener los puntos de corte estadísticamente establecidos para los dos antimicrobianos. Para 


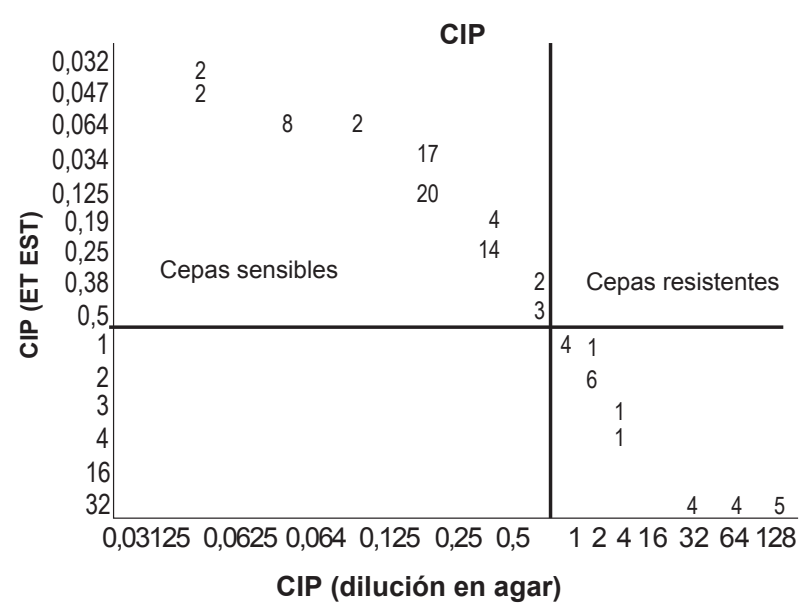

Figura 1. Gráfico de Scatterplot susceptibilidad antimicrobiana Bartonella bacilliformis. Correlación entre E-Test y dilución en agar $(\mu \mathrm{g} / \mathrm{mL})$

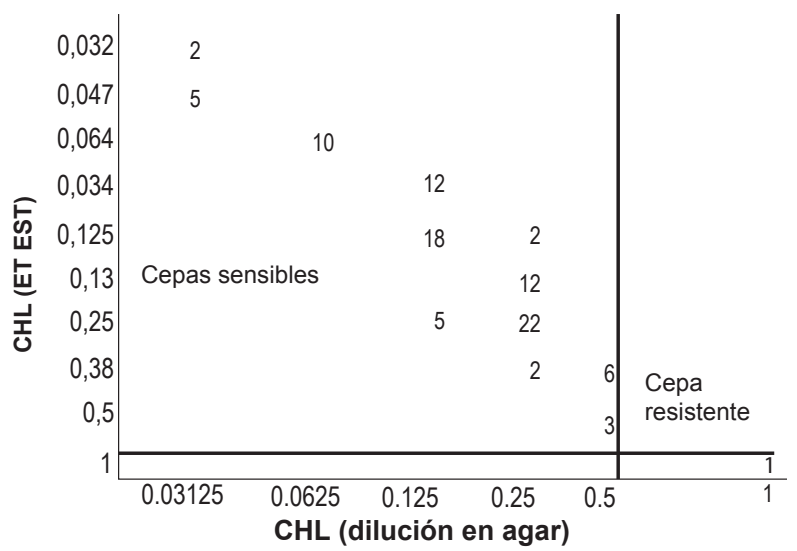

Figura 2. Gráfico de Scatterplot susceptibilidad antimicrobiana Bartonella bacilliformis. Correlación entre zonas E-Test y dilución en agar $(\mu \mathrm{g} / \mathrm{mL})$

determinar la correlación entre la MIC $(\mu \mathrm{g} / \mathrm{mL})$ y el diámetro de la zona de inhibición del test de disco difusión de cada antimicrobiano, se aplicó el software WHONET, utilizando scatterplot graphs ${ }^{(19,20)}$.

Mediante la ejecución de tres métodos de laboratorio se determinó La frecuencia de cepas de Bartonella bacilliformis sensibles y resistentes a CHL y CIP, fueron calculados en porcentajes correspondientes a las áreas endémicas. Para la evaluación de la asociación entre la cepas resistentes y el tratamiento antimicrobiano previo de los pacientes, se utilizó el coeficiente de correlación tetracórica y STATA v12.0.

\section{CONSIDERACIONES ĖTICAS}

Cada cepa evaluada fue codificada con la finalidad de mantener la confidencialidad de la información. El estudio contó con la aprobación del Comité de Investigación y Ética del Instituto Nacional de Salud-Perú.

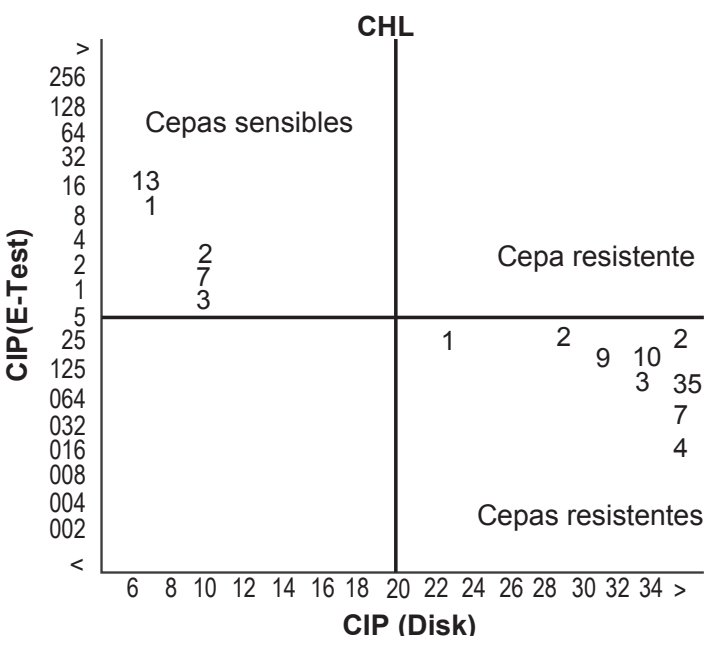

Figura 3. Gráfico de Scatterplot susceptibilidad antimicrobiana Bartonella bacilliformis. Correlación entre zonas E-Test $(\mu \mathrm{g} / \mathrm{mL})$ y Disco difusión (mm)

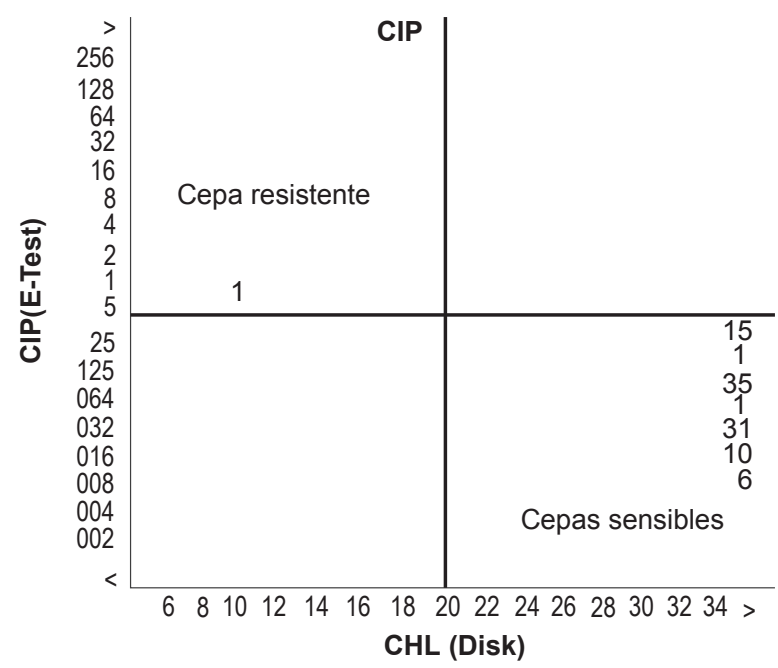

Figura 4. Gráfico de Scatterplot susceptibilidad antimicrobiana Bartonella bacilliformis. Correlación entre zonas E-Test $(\mu \mathrm{g} / \mathrm{mL})$ y disco difusión ( $\mathrm{mm}$ )

Tabla 1. Susceptibilidad antimicrobiana de Bartonella bacilliformis

\begin{tabular}{lcc}
\hline & Cepas sensibles & Cepas resistentes \\
\hline E-test & & \\
Ciprofloxacino & 74 & 26 \\
Cloranfenicol & 99 & 1 \\
Dilución en agar & & \\
Ciprofloxacino & 74 & 26 \\
Cloranfenicol & 99 & 1 \\
Disco difusión & & \\
Ciprofloxacino & 74 & 26 \\
Cloranfenicol & 99 & 1 \\
\hline
\end{tabular}


Tabla 2. Susceptibilidad antimicrobiana de Bartonella bacilliformis en áreas endémicas de la enfermedad de Carrión en Perú

\begin{tabular}{lccccc}
\hline & Susceptibilidad & \multicolumn{2}{c}{ CHL (\%) } & \multicolumn{2}{c}{ CIP (\%) } \\
\hline Ancash & $\mathrm{S}$ & 14 & $(93,3)$ & 11 & $(73,3)$ \\
$(\mathrm{N}=15)$ & $\mathrm{R}$ & 1 & $(6,7)$ & 4 & $(26,7)$ \\
Cajamarca & $\mathrm{S}$ & 20 & $(100)$ & 18 & $(90,0)$ \\
$(\mathrm{N}=20)$ & $\mathrm{R}$ & 0 & & 2 & $(10,0)$ \\
Cusco & $\mathrm{S}$ & 30 & $(100)$ & 14 & $(46,7)$ \\
$(\mathrm{N}=30)$ & $\mathrm{R}$ & 0 & & 16 & $(53,3)$ \\
La Libertad & $\mathrm{S}$ & 5 & $(100)$ & 5 & $(100)$ \\
$(\mathrm{N}=5)$ & $\mathrm{R}$ & 0 & & 0 & \\
Lima & $\mathrm{S}$ & 30 & $(100)$ & 26 & $(86,7)$ \\
(N=30) & $\mathrm{R}$ & 0 & & 4 & $(13,3)$ \\
Total cepas & $\mathrm{S}$ & 99 & $(99,0)$ & 74 & $(74,0)$ \\
(N=100) & $\mathrm{R}$ & 1 & $(1,0)$ & 26 & $(26,0)$ \\
\hline
\end{tabular}

S: sensible; R: resistente CHL: clorafenicol; CIP: ciprofloxacoino

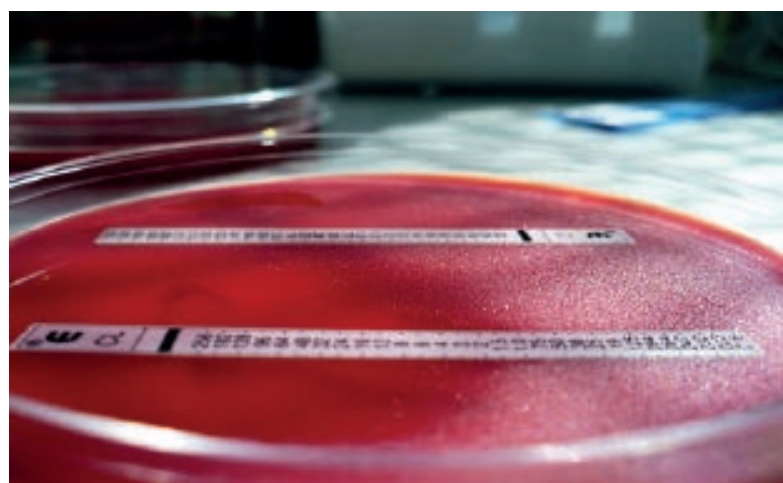

Figura 5. Cepa de Bartonella bacilliformis procedente de departamento de Ancash, mostrando resistencia a las tiras de E-test ciprofloxacin $(>32 \mu \mathrm{g} / \mathrm{mL})$ y cloranfenicol $(6 \mu \mathrm{g} / \mathrm{mL})$.

\section{RESULTADOS}

Los puntos de corte para la evaluación de la susceptibilidad antimicrobiana de cepas de Bartonella bacilliformis a $\mathrm{CHL}$ y CIP, mediante los métodos de E-test, dilución en agar y disco difusión, utilizando agar Columbia suplementado con $10 \%$ de sangre desfibrinada de carnero, fueron establecidos para el microorganismo en el presente trabajo, siguiendo la metodología de la British Society for Antimicrobial Chemotherapy (BSAC).

Los puntos de corte estadísticamente determinados presentaron los mismos valores para $\mathrm{CHL}$ y $\mathrm{CIP}$, habiéndose obtenido para los métodos de dilución en agar y E-test los valores de $\leq 0,5 \mu \mathrm{g} / \mathrm{mL}$ (cepas sensibles) $y \geq 1 \mu \mathrm{g} / \mathrm{mL}$ (cepas resistentes). Para disco difusión, los valores obtenidos del diámetro de los halos de inhibición, para ambos antimicrobianos fueron de $\geq$ $21 \mathrm{~mm}$ (cepas sensibles) y $\leq 20 \mathrm{~mm}$ (cepas resistentes). El gráfico de Scatterplot resultante, permite la comparación directa de los resultados de los aislamientos de acuerdo a los métodos evaluados. Esto confirma que existe una

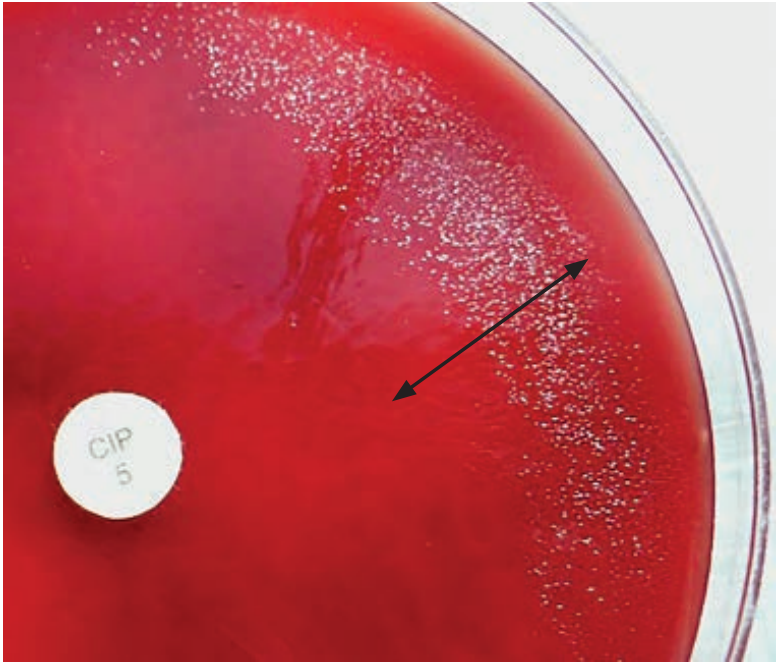

Figura 6. Cepa de Bartonella bacilliformis sensible a ciprofloxacino halo de inhibición $(58 \mathrm{~mm})$.

Método de disco difusión - CIP $(5 \mu \mathrm{g})$

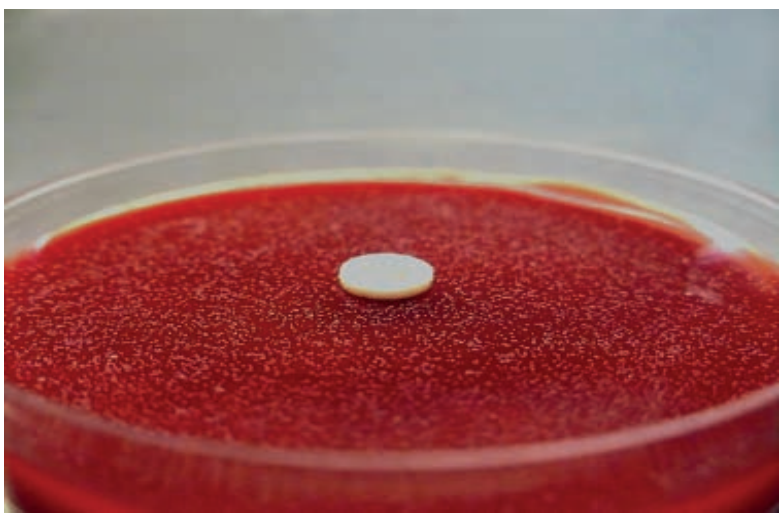

Figura 7. Cepa de Bartonella bacilliformis resistente a CIP, crecimiento confluente alrededor del disco de CIP $(5 \mu \mathrm{g})$, ausencia de halo de inhibición disco difusión $(6 \mathrm{~mm})$

correlación positiva entre los valores de MIC y las zonas de inhibición en los tres métodos evaluados, habiéndose obtenido los mismos resultados para cepas sensibles y resistentes (Figura 1-4).

Usando los puntos de corte establecidos en la investigación, la resistencia fenotípica in vitro a CIP en las 100 cepas evaluadas fue del $26 \%$ y solo $1 \%$ resistente a $\mathrm{CHL}$. El mayor número de cepas resistentes a CIP, fueron las procedentes de Quillabamba-Cusco, 16/26 (61,5\%), Huarochirí-Lima, 4/26 (15,4\%), Ancash, 4/26 (15,4\%) y Jaén-Cajamarca, $2 / 26(7,7 \%)$. La cepa resistente a $\mathrm{CHL}$ fue aislada de un paciente del departamento de Ancash 1/100 (1\%) (Tabla 3). No fue posible comparar con precisión la resistencia fenotípica in vitro de cepas de Bartonella bacilliformis circulantes en cada región endémica del Perú, por la limitada disponibilidad de 


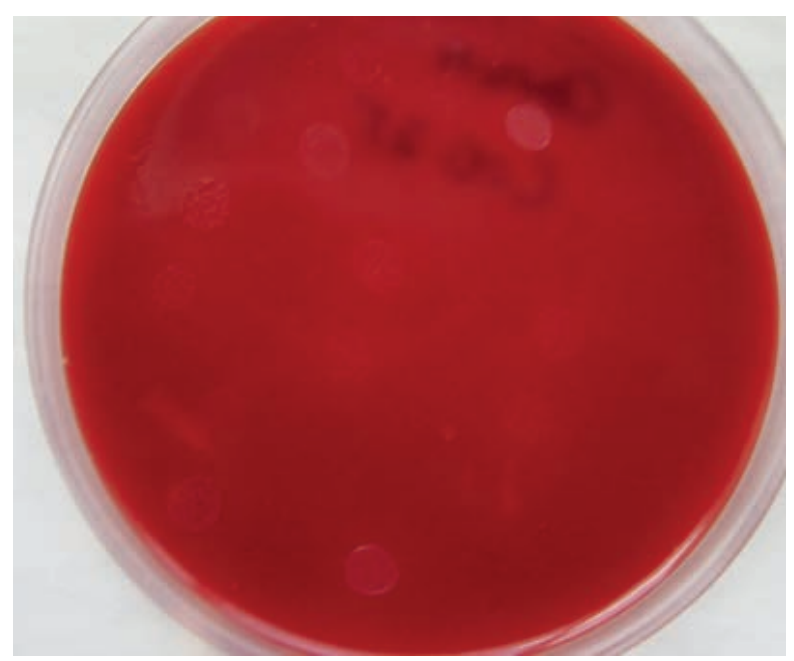

Figura 8. Crecimiento de cepas de Bartonella bacilliformis resistentes a CIP, crecimiento en los puntos de inoculación. Dilución en agar $>32 \mu \mathrm{g} / \mathrm{mL}$

aislamientos, especialmente del departamento de La Libertad.

En la evaluación de la susceptibilidad antimicrobiana mediante el método de E-test, 74 cepas presentaron inhibición del crecimiento bacteriano entre las MIC 0,016-0.5 $\mu \mathrm{g} / \mathrm{mL}$ de CIP, confirmándose su sensibilidad al antimicrobiano; la misma característica fue observada en 99 aislamientos enfrentados a las tiras de CHL; 26 cepas presentaron patrones diferentes, 13 aislamientos desarrollaron por encima de la máxima concentración de CIP (>32 $\mu \mathrm{g} / \mathrm{mL}$ ) (Figura 3 ) y las 13 cepas restantes desarrollaron hasta las concentraciones $\geq 1-4 \mu \mathrm{g} / \mathrm{mL}$, demostrando ser resistentes in vitro al antimicrobiano. Una cepa presentó crecimiento hasta la concentración de $6 \mu \mathrm{g} / \mathrm{mL}$ de la tira embebida con CHL (Figura 1 y 2).

Las 74 cepas determinadas como sensibles por el método de E-test, presentaron halos de inhibición entre 40 a 58 $\mathrm{mm}$; alrededor de los discos de CIP $(5 \mu \mathrm{g})$ y $\mathrm{CHL}(30 \mu \mathrm{g})$, confirmándose su sensibilidad a ambos antimicrobianos por el método de disco difusión (Figura 5). Por este método las 26 cepas determinadas como "resistentes" por E-test, presentaron patrones similares de inhibición a los discos de CIP, 14 aislamientos mostraron crecimiento confluente de colonias alrededor del disco (Figura 7); 8 cepas, presentaron halos de inhibición entre 17-18 mm y las 4 restantes halos entre 19 a $20 \mathrm{~mm}$. Mientras que para $\mathrm{CHL}$, una cepa presentó un halo de inhibición de $17 \mathrm{~mm}$.

Por el método de Dilución en agar, se confirmaron los resultados obtenidos en los métodos previos evaluados, 74 cepas desarrollaron en placas de concentraciones entre los rangos de 0,0312 a $0,5 \mu \mathrm{g} / \mathrm{mL}$ de CIP, 26 cepas presentaron crecimiento en los puntos de inoculación en placas de concentraciones mayores a $1 \mu \mathrm{g} / \mathrm{mL} ; 13$ aislamientos presentaron crecimiento en las placas de concentraciones $>32 \mu \mathrm{g} / \mathrm{mL}$. Para $\mathrm{CHL}$ se observó crecimiento bacteriano de 99 cepas, en las placas de concentraciones del antimicrobiano entre 0,0312 a $0,5 \mu \mathrm{g} / \mathrm{mL}$, solo 1 cepa presentó crecimiento hasta la concentración $16 \mu \mathrm{g} / \mathrm{mL}$ (Figura 1 y 2).

Por la revisión de las fichas clínicas de los pacientes de quienes procedían las 26 cepas resistentes a CIP, se determinó que 17 nunca recibieron tratamiento de CIP, mientras que los 9 restantes recibieron CIP/500 mg/12 $\mathrm{h} / 10$ días. El paciente del que procedía la cepa resistente a CHL no recibió ningún tratamiento antimicrobiano.

En la evaluación estadística de estos resultados, mediante el coeficiente de correlación tetracórica de STATA V.12.0, se obtuvo un valor $p<0,0001$ para ambos casos, demostrando que no existe asociación entre la resistencia antimicrobiana y el tratamiento recibido.

\section{DISCUSIÒN}

Estudios realizados a nivel nacional e internacional que evaluaron la susceptibilidad antimicrobiana in vitro de cepas de Bartonella bacilliformis, mediante el método de microdilución en placa y E-test, determinaron que Bartonella bacilliformis y otras especies del género son altamente susceptibles a la mayoría de drogas antimicrobianas como betalactámicos, penicilina, aminoglucósidos, cefalosporinas y quinolonas (12,14). Sin embargo, nuestro estudio muestra una elevada resistencia para CIP y casi nula resistencia para CHL, la cual no era la esperada, dado que este medicamento se dejó de emplear por los frecuentes reportes de falta de respuesta clínica al tratamiento. Estos resultados probablemente sean debido al reducido número de cepas del departamento de Ancash evaluadas, lugar donde se reportaron casos de fracaso a la terapia antimicrobiana con CHL. Referente a la resistencia a CIP, este medicamento es considerado de primera línea en el manejo de la EC en diversas guías, tanto nacionales como internacionales $(4,5,6,15)$, las cuales deberían ser reevaluadas.

Las diferencias con otros estudios pueden deberse a que estos fueron desarrollados en un número reducido de cepas de Bartonella bacilliformis ${ }^{(13)}$, por consiguiente, los resultados obtenidos podrían no ser significativos y no expresar la verdadera situación de la susceptibilidad antimicrobiana in vitro de las cepas de Bartonella bacilliformis, ni la real magnitud de probables cepas resistentes circulantes en el Perú; además de que el uso indiscriminado de CIP y otros antibióticos podrían haber modificado los resultados obtenidos en dichos estudios ${ }^{(9)}$, ello explicaría los actuales casos de fallas en la terapia antibiótica establecida para el tratamiento de pacientes con EC. 
Bartonella bacilliformis es un microorganismo de crecimiento lento que requiere medios enriquecidos y temperaturas óptimas para su crecimiento, por lo que los tres métodos de laboratorio desarrollados, fueron diseñados y especialmente adecuados para el presente estudio. Habiendo determinado que los métodos de E-test y Disco Difusión resultan más convenientes para la evaluación de la susceptibilidad antimicrobiana in vitro de cepas de Bartonella bacilliformis, por ser métodos de fácil ejecución, que pueden ser desarrollados en laboratorios intermedios; mientras que el método de Dilución en agar, presenta como desventajas el elevado costo de los reactivos y laboriosos procedimientos para su desarrollo.

La presente investigación evaluó la susceptibilidad antimicrobiana in vitro de 100 cepas de Bartonella bacilliformis, procedentes de cinco áreas endémicas con frecuentes brotes de la enfermedad. El mayor porcentaje (16\%) de cepas resistentes a CIP, procedieron del departamento de Cusco, donde uno de los últimos brotes importantes se registró el año 2002, después del fenómeno El Niño ${ }^{(16)}$ y posteriormente los años 2008 y 2009 , períodos en los cuales se aislaron las cepas que fueron evaluadas en el estudio. El limitado número de cepas disponibles de los departamentos de La Libertad y Ancash no permitió obtener información representativa de la situación real de la susceptibilidad antimicrobiana in vitro de las cepas de Bartonella bacilliformis circulantes en ambos departamentos, sobre todo en Ancash, departamento donde se reportaron frecuentes fallas en la terapia antimicrobiana en pacientes tratados con $\mathrm{CHL}$.

Cabe mencionar que lamentablemente no se disponen de cepas de los grandes brotes de los años 2002-2004 que ocurrieron en Cusco y Ancash, motivo por el cual no fue posible incluir este importante grupo en la presente investigación.

La resistencia a CIP no es nueva, otros estudios desarrollados mediante procedimientos moleculares evaluando cepas de Bartonella bacilliformis, aisladas en 1957,1970 y 1996 , encontraron que estas cepas tenían resistencia constitutiva a las quinolonas relacionada a la presencia de alanina en posición 91 y 85 de las dianas de las quinolonas (GyrA y ParC) ${ }^{(7,8)}$. Estos resultados ya nos alertaban de la resistencia intrínseca y constitutiva antes de la introducción de las quinolonas en la práctica clínica, por lo que su inclusión en las normas técnicas y recomendaciones clínicas sobre el uso de CIP para el tratamiento de la EC en el Perú deberían ser reevaluadas considerando su rápida resistencia.

Esto es importante en el contexto peruano, dado que la evaluación de la eficacia del tratamiento antimicrobiano de la enfermedad de Carrión, actualmente solo se realiza clínicamente de acuerdo con la evolución y respuesta clínica del paciente. No se han desarrollado estudios, hasta el momento, de evaluación bacteriológica de los antibióticos una vez finalizado el tratamiento, estas evaluaciones, en caso de realizarlas, proporcionarían evidencias importantes del comportamiento in vitro del microorganismo respecto a la terapia antimicrobiana utilizada. Si el principal reservorio es la persona que sufrió la enfermedad, el mejor antibiótico seria aquel que permita eliminar la bacteriemia después de terminado el tratamiento, constituyendo la principal medida de prevención y control de la EC en áreas endémicas; siendo todas estas recomendaciones para futuras investigaciones.

El estudio tiene algunas limitaciones; el número de las cepas no es representativa de la totalidad del Perú, sin embargo, corresponde a aproximadamente el 50\% de cepas aisladas en el periodo 2005-2011 en el Laboratorio de Metaxénicas Bacterianas del Instituto Nacional de Salud, que es el centro de referencia peruano para la caracterización bacteriológica de Bartonella bacilliformis. Actualmente, se viene realizando la evaluación de la susceptibilidad antimicrobiana a aminoglucósidos, otras fluoroquinolonas, macrólidos, penicilinas, cefalosporinas, tetraciclina y otros, además de la caracterización molecular de los genes involucrados en la resistencia genotípica de este microorganismo; estudio que permitirá complementar los resultados obtenidos hasta el momento.

En conclusión, el presente estudio es el primer análisis que incluye un número importante de cepas de Bartonella bacilliformis, mostrando los elevados niveles de resistencia antimicrobiana in vitro de $26 \%$ de cepas de Bartonella bacilliformis a las quinolonas de segunda generación (CIP), a diferencia del $1 \%$ de resistencia encontrada para CHL. En los tres métodos evaluados, se obtuvieron resultados similares para cada cepa estudiada, lo cual confirma la sensibilidad o resistencia in vitro de Bartonella bacilliformis a CIP y CHL.

Porconsiguiente, sesugierelaevaluacióndelosesquemas de tratamiento utilizados en la terapia antimicrobiana de los pacientes afectados por la enfermedad de Carrión. Así mismo, es necesario fortalecer el sistema de vigilancia de la resistencia antimicrobiana de cepas de Bartonella bacilliformis a nivel nacional y continuar con el desarrollo de investigaciones que permitan determinar molecularmente los mecanismos por los cuales este microorganismo elude la acción de los antimicrobianos utilizados hasta el momento.

Agradecimientos: al Dr. Charles Huamaní por el asesoramiento prestado a los autores para la redacción del artículo. 
Contribuciones de autoría: GMM participó en la concepción y diseño del trabajo, análisis, interpretación de datos y redacción del manuscrito. DFL participó en el análisis, interpretación de datos y redacción del manuscrito. Los autores revisaron en forma crítica las versiones preliminares del manuscrito y aprobaron la versión final.
Fuente de financiamiento: Instituto Nacional de Salud.

Conflictos de interés: los autores declaran no tener conflicto de interés en la publicación de este artículo.

\section{REFERENCIAS BIBLIOGRÁFICAS}

1. Nunura JM. La Vigilancia Epidemiológica en Salud Pública de la enfermedad de Carrión. Bol Epidemiol (Lima). 2012;21(15):245-46.

2. Bass JW, Vincent JM, Person DA. The expanding espectrum of Bartonella infections: I. Bartonellosis and trench fever. Pediatr Infect Dis J. 1997;16(1):2-10.

3. Ministerios de Salud del Perú. Enfermedad de Carrión (bartonelosis) en el Perú. Módulos Técnicos. Serie de documentos monográficos. Lima: MINSA/INS; 2001.

4. Tarazona A, Maguiña C, López de Guimaraes D, Montoya M, Pachas P. Terapia antibiótica para el manejo de la Bartonelosis o enfermedad de Carrión en el Perú. Rev Peru Med Exp Salud Publica. 2006;23(3):188-200.

5. Norma Técnica para la Atención de la Bartonelosis o Enfermedad de Carrión en el Perú. NTS No 048-MINSA/ DGSP-V.01; Lima. (Julio del 2006).

6. Pachas P. Generando evidencias para las políticas públicas de prevención y control: Experiencia en la enfermedad de Carrión en el Perú [internet]. En: VII Congreso Científico Internacional del Instituto Nacional de Salud, Lima, Perú. 07 al 09 de noviembre de 2013 [citado el 14 de julio de 2015]. Disponible en: http://www.bvs.ins. gob.pe/congresos/index.php/201311-05-19-25-01/congreso\#jueves-7mañana

7. del Valle LJ, Flores L, Vargas M, Garciade-la-Guarda R, Quispe RL, Ibañez ZB, et al. Bartonella bacilliformis, endemic pathogen of the Andean region, is intrinsically resistant to quinolones. Int J Infect Dis. 2010;14(6):506-10. doi: 10.1016/j.ijid.2009.07.025.

8. Minnick MF, Wilson ZR, Smitherman LS, Samuels DS. gyrA mutations in ciprofloxacin-resistant Bartonella bacilliformis strains obtained in vitro. Antimicrob Agents Chemother. 2011;47(1):383-6.

9. Biswas S, Raoult D, Rolain JM. Molecular mechanisms of resistance to antibiotics in Bartonella bacilliformis. J Antimicrob Chemother. 2007;59(6):1065-70.

10. Sánchez Clemente N, Ugarte-Gil CA, Solórzano N, Maguiña C, Pachas P, Blazes D, et al. Bartonella bacilliformis: a systematic review of the literature to guide the research agenda for elimination. PLoS Negl Trop Dis. 2012;6(10):e1819. doi: 10.1371/ journal.pntd.0001819.

11. Ives TJ, Manzewitsch P, Regnery RL, Butts JD, Kebede M. In vitro susceptibilities of Bartonella henselae, B. quintana, B. elizabethae, Rickettsia rickettsii, $R$. conorii, $R$. akari, and $R$. prowazekii to macrolide antibiotics as determined by immunofluorescentantibody analysis of infected Vero cell monolayers. Antimicrob Agents Chemother. 1997;41(3):578-82.

12. Dörbecker C, Sander A, Oberle $\mathrm{K}$, Schulin-Casonato $\mathrm{T}$. In vitro susceptibility of Bartonella species to 17 antimicrobial compounds: comparison of Etest and agar dilution. J Antimicrob Chemother. 2006;58(4):784-8.

13. Sobraqués M, Maurin M, Birtles RJ, Raoult D. In vitro susceptibilities of four Bartonella bacilliformis strains to 30 antibiotic compounds. Antimicrob Agents Chemother. 1999;43(8):2090-2.

14. Novelli S. Determinación de la susceptibilidad antibiótica de 14 antibióticosparaBartonellabacilliformis por métodos microbiológicos e inmunohistoquímicos [Tesis bachiller]. Lima: Universidad Peruana Cayetano Hredia; 2004.
15. Pérez-Martínez L, Blanco JR, Oteo JA. [Treatment of human infections caused by Bartonella spp.]. Rev Esp Quimioter. 2010;23(3):109-14. [Article in Spanish]

16. Quispe R. Caracterización molecular de los genes asociados a la resistencia antimicrobiana en Bartonella bacilliformis [Tesis bachiller]. Lima: Facultad de Ciencias Biológicas, UNMSM; 2009.

17. Ruiz J. Mechanisms of resistance to quinolones: target alterations, decreased accumulation and DNA gyrase protection. J Antimicrob Chemother. 2003;51(5):1109-17.

18. Tarazona D, Padilla C, Caceres O, Montenegro JD, Bailon H, Ventura G, et al. Whole Genome Sequencing and Comparative Analysis of Bartonella bacilliformis Strain INS, the Causative Agent of Carrion's Disease. Genome Announc. 2013;1(1). pii: e00053-12. doi: 10.1128/genomeA.00053-12.

19. Mac Gowan AP, Wise R. Establishing MIC breakpoints and the interpretation of in vitro susceptibility tests. J Antimicrob Chemother. 2001;48 Suppl 1:17-28.

20. British Medical Association and Royal Pharmaceutical Society of Great Britain. British National Formulary, $40^{\text {th }}$ ed. London: British Medical Association and Royal Pharmaceutical Society of Great Britain, 2000.

Correspondencia: Giovanna Mendoza Mujica

Dirección: Cápac Yupanqui 1400 Jesús

María, Lima 11, Perú

Teléfono: (511) 7481111 anexo 2134

Correo electrónico:gmendoza@ins.gob.pe, gmm2407@gmail.com 